\title{
Integrating IT Skills into a Business School's Programmes
}

\author{
Janice Whatley, Simon Ireland, and Richard Bell \\ Salford Business School, University of Salford, Manchester, UK
}

\author{
j.e.whatley@salford.ac.uk, s.ireland@salford.ac.uk, \\ r.bell@salford.ac.uk
}

\begin{abstract}
Employers are looking for a wider range of skills in graduates than they have in the past. These employability skills include: using IT, working in a team, being innovative, communication and an ability to manage their own learning. These qualities are enshrined in the Personal Development Planning (PDP) element of present day undergraduate programmes of study. The problem facing Salford Business School was to include experiences to develop employability skills within a new first year module, which was to be delivered to all of the wide range of undergraduate programmes delivered. The ability levels of students, as they embarked on their undergraduate studies, varied widely, so providing learning activities, which students of all ability levels would engage with, was difficult. One aim of the module design was to embed IT skills in this module, so that students were made aware of the wider applications of IT within business, and had the opportunity to use the full range of available business IT resources, and this was taking the students' previous IT skills to a further dimension.

This paper describes the new first year module and how IT skills are embedded. It then evaluates the first delivery of the module through student feedback and the process of module evaluation. Findings indicate that the students appreciated the opportunities to develop the various IT and employability skills offered, and regarded them as important for their future prospects.
\end{abstract}

Keywords: Employability skills, IT skills, Curriculum development, Group working

\section{Introduction}

A restructuring of the schools within the University of Salford (UK) resulted in the Information Systems school becoming merged with the Management, Leisure and Hospitality, and Finance and Accounting schools, to form a new Business School. One of the aims of this merger was to enrich the learning experience of the students within the undergraduate programmes of these discipline areas, with business IT content. A new set of undergraduate modules of study were introduced in the 2009/10 academic year, including a module called Management Development Pro-

Material published as part of this publication, either on-line or in print, is copyrighted by the Informing Science Institute. Permission to make digital or paper copy of part or all of these works for personal or classroom use is granted without fee provided that the copies are not made or distributed for profit or commercial advantage AND that copies 1) bear this notice in full and 2) give the full citation on the first page. It is permissible to abstract these works so long as credit is given. To copy in all other cases or to republish or to post on a server or to redistribute to lists requires specific permission and payment of a fee. Contact Publisher@InformingScience.org to request redistribution permission. gramme, which would include various employability skills such as IT, team working and communication skills, together with an opportunity for students to reflect on their learning.

This paper describes the format and content of the new module, learning activities included and evaluates the outcomes of the module, from the students' perspective. 


\section{Background}

In reviewing the literature for this study, several areas were found to be relevant, such as learning and teaching, employable skills and curriculum design. This section will review the supporting literature around the need for graduates with so called "employability" skills, the sorts of learning activities that promote these skills and module design for enabling students to develop appropriate skills.

The UK government has made various recommendations, including certain skill areas in the teaching curriculum in secondary and tertiary education, since the 1950's. Often these were called "core skills", "key skills", "transferable skills" or "general skills", but whatever the name they were all aimed at preparing people for the world of work. Typically these skills comprised literacy, numeracy and information technology, and in the UK these have been enshrined in compulsory education for many years (Hyland and Johnson, 1998). More recently, skills such as "working with others", "presentation", "problem solving" and "managing own learning", have been added, in an effort to broaden the skills to those that make individuals "employable". A survey in 2007 found that $64 \%$ of employers regarded employability skills more highly than the discipline knowledge of a student's undergraduate degree programme (Prospects, 2010). Another survey covering the European Union confirms the importance of team working skills, with $98 \%$ of employers questioned saying this was important in recruitment, and also the ability to adapt to different situations (97\%) and knowledge of foreign languages (67\%) (Gallup, 2010). There are many benefits for employers when higher education institutions teach employability skills, including staff that will contribute to the employer's competitive edge, improved individual performance and resulting profitability for the organization, and having staff with effective team working capabilities (Hordyk, 2007).

Higher education institutions are being encouraged to play their part in preparing students for work, by teaching skills associated with employability, such as information and communication technology (ICT) and team working (Yorke \& Knight, 2003; Prichard et al., 2006). Dacre Pool and Sewell (2007) suggest that working in a team, creativity, planning and communication are important graduate skills. The employers' need for graduates with employability skills, including ICT and team working, has driven much of the curriculum development in the past 20 years, but defining appropriate skills and how they can be learned, or acquired, is problematical. Hyland and Johnson (1998) argue that these employability skills must be situated within a specific context, and cannot be taught as such, but are acquired through opportunities for experiences, provided by the curriculum. Any skills should be closely related to the context with its associated body of knowledge, so that knowledge of a subject is combined with skills to apply it appropriately. Of course employability skills applied in the workplace may be different to the experiences that can be logistically provided for students in the higher education environment, in particular skills associated with effective communication and team working.

Over the past few years, the Quality Assurance Agency for Higher Education in the UK, has produced "benchmark statements" for bachelor's degrees with honours, which describe the nature and characteristics that these programmes should possess. The general business and management and librarianship and information management subject areas both include elements of team working, for example, from general business and management:

"effective performance, within a team environment, including leadership, team building, influencing and project management skills" (Education, 2007);

and from librarianship and information management:

"Work in groups or teams as a leader or participate in a way that contributes effectively to the group's tasks" (Education, 2000) 
A trial by Dunne and Rawlins (2000) of a series of modules to promote team working skills at university, in conjunction with the company BP, has shown that structured training in team skills provides a "safe" learning environment, and as students develop a responsibility for their own learning, through team working and project working, they are better prepared for lifelong learning.

Although the term "learning" in difficult to define, most learning theorists agreed that learning is "a process by which behaviour is changed, shaped or controlled" (Knowles, 1990, p. 13) but Bruner went further to suggest that learning is "...growth, development of competencies, and fulfilment of potential" (Knowles, 1990, p. 13), which places more emphasis on intellectual development and acquiring skills. Learning is not seen in itself, but the products of learning are observed, in what people say, write or do. Education is "activity undertaken ... to effect changes in the knowledge, skill and attitudes of individuals, groups or communities" (Knowles, 1990, p. 10). Knowles' definitions apply to adults, and as undergraduate students are adult learners, a degree of intellectual development would be expected as well as learning the theory and associated skills pertaining to a particular domain.

Learning may also be viewed as bipolar, comprising two metaphors for learning: learning as acquisition or learning as participation (Sfard, 1998). The acquisition metaphor refers to learning facts, usually related to the context of the learning, whilst the participation metaphor refers to learning as being a part of an activity, in order to gain experience of using learned material. Hodkinson and Macleod (2007) add construction (or formation) and becoming as desirable outcomes of the learning process. However, much of the learning of humans takes place in a social situation, and observing others is one way of learning rules, skills, strategies and so on, the basis of "social cognition", or cognitive learning (Schunk, 2000, p. 24). Thus imitation of others to reproduce the observed behaviour, as in apprenticeships, is applicable to learning about using practical skills, and suggests the use of team working as a vehicle for development.

Collaborative and co-operative learning is becoming more important in higher education, both within and outside of team activities, and may be defined as "a situation in which two or more people learn or attempt to learn something together " (Dillenbourg, 1999). The number of people involved may range from two to several hundred; learning may be a joint activity or simply reading material together, and the activity may be face to face or online. Many academics use the terms collaborative and co-operative interchangeably, when referring to student team working. But looking at definitions does identify crucial differences: co-operative means "working with others for a common end, purpose or benefit", and collaborative means "working together in an endeavour, in a joint intellectual effort" (http://dictionary.reference.com). McConnell (2000, p. 15) defines co-operative learning as "...learning involving working together on some task or issue in a way that promotes individual learning through processes of collaboration in groups". In the context of group working, students often work together on a project, and are expected to work together to produce a common set of outputs, i.e. working co-operatively, but also may be working collaboratively to learn specific tasks or theory, which may contribute to the outputs of the project.

The reflective nature of personal development planning (PDP) is of increasing importance in higher education, and is recognised by employers as an indicator of an individual who is capable of learning from experiences. Edwards (2005) reporting on feedback from employers of graduates, said that engaging in the process of reflection is just as important as the resulting portfolio of evidence. So an ability to reflect on the experience of the learning activity is just as important as achievement of the actual product of the learning.

Designing learning activities that provide suitable experiences for developing the recognised employability skills of: IT, communication (including web enabled), collaboration in groups and 
Integrating IT Skills into a Business School's Programmes

reflection, requires a degree of lateral thinking, if educators are to provide experiences that may go some way to simulating these aspects of the workplace environment. The next section describes the new module that was designed to help students to develop a range of employability skills.

\section{The Management Development Programme Module}

As its name suggests, the new module was designed for developing the students' management skills. The aims of the module were as follows (taken from the module specification):

1. To enhance professional skills for learning in Higher Education

2. To develop students who are employable, confident, self reliant and enterprising

3. To improve management practice development

The proposed module needed to incorporate elements that would help the students to develop their skills in learning, in preparation for lifelong learning, elements to develop a range of employability skills and elements that would integrate management practice with skills development. Although these elements had been incorporated into other modules previously, skills development had not been explicit, so some students did not recognize their achievements within the wider context of employability skills. This was an opportunity to bundle these activities together, deliver the content to all of the first year students and allow students from different degree programmes to learn together. These were to be achieved through a range of learning and teaching strategies, as stated in the module specification:

"The learning and teaching strategy will focus on a series of keynote lecturers, seminars, workshops and tutorials supplemented with formative assessments throughout via on-line assessments and Personal Tutor feedback. The learning will include support for assessment elements from concurrent modules, including; report writing, referencing, plagiarism, presentations integrated within the portfolio assessment elements and Personal Development Planning (PDP). "(Taken from the Module Specification, 2009)

A weekly lecture and a seminar on a fortnightly basis were planned. Assessment was to be through a portfolio of learning activities and assessed elements, and online tests to build up the PDP of each individual. Group working was included within assessment as well as in tutorial activities, so that experience of group working, managing groups and project management were provided. There was also an emphasis on entrepreneurship and innovation in the seminar activities and the assessment, to provide an opportunity to think about the processes of starting a new business. The following list of curriculum content reflects the purpose of the module, and is used in this paper to evaluate the success of the module against qualities desired to be achieved in students:

1. Effectively use Microsoft Office suite (Word, Excel, PowerPoint, Internet Explorer) email, web 2.0 and the University Virtual Learning Environment;

2. Access sources of secondary data and business reports using the library, both traditional and electronic;

3. Present, analyse and interpret financial/statistical data using visual displays and number summaries;

4. Communicate in a clear, systematic and concise way for a range of different purposes and audiences, using a range of current and emerging technologies;

5. Plan and manage projects to solve simple business problems;

6. Recognise reasons for success and failure of group work from theory and practice;

7. Reflect on personal skills development and learning. 
It can be seen that the content of the module was deliberately kept broad, so that finer detail could be specified as the module was delivered for the first time, and changes in future delivery cycles could be added without the need for amending the module specification each year. Developing the module went though stages from ideas for lectures and portfolio activities, to agreed topics for lectures and assessment tasks. Seminar activities were designed to be something that the students could accomplish within the two hour slot allocated for the session, so that students could leave the session with a sense of achievement. The lecture schedule was shaped by appropriate keynote lecturers, as well as ensuring that lectures supporting learning activities were timely.

Table 1 - The range of learning activities over the two semesters.

\begin{tabular}{|c|c|c|c|}
\hline Date & Learning activity & Main topic & Description \\
\hline October & Assignment 1 & Excel & $\begin{array}{l}\text { Design a suitable spreadsheet to produce } \\
\text { a cash flow statement to calculate and } \\
\text { summarise their personal finances over a } \\
\text { six month period }\end{array}$ \\
\hline November & Seminar & Using the library & $\begin{array}{l}\text { Complete a worksheet to demonstrate } \\
\text { competence at research using library re- } \\
\text { sources }\end{array}$ \\
\hline November & Seminar & PowerPoint & $\begin{array}{l}\text { Using PowerPoint the students had to } \\
\text { work in small teams to produce and pre- } \\
\text { sent an idea for a business venture or } \\
\text { product }\end{array}$ \\
\hline December & Seminar & Publisher & $\begin{array}{l}\text { Working in the same small teams, the } \\
\text { students had to produce some marketing } \\
\text { literature to support their business ven- } \\
\text { ture }\end{array}$ \\
\hline January & Assignment 2 & $\begin{array}{l}\mathrm{CV} \text { and covering } \\
\text { letter }\end{array}$ & $\begin{array}{l}\text { The students had to find an appropriate } \\
\text { job vacancy, prepare their CV and write a } \\
\text { covering letter to apply for that job va- } \\
\text { cancy }\end{array}$ \\
\hline February & Seminar & Using the e-library & $\begin{array}{l}\text { Complete a worksheet to demonstrate } \\
\text { competency in using the e-library to find } \\
\text { resources }\end{array}$ \\
\hline March & Assignment 3 & Group presentation & $\begin{array}{l}\text { "Your company (fictitious from your } \\
\text { field of study) is required to attend an } \\
\text { exhibition to publicise an event, product } \\
\text { or service. You are required to produce } \\
\text { and display suitable material for the ex- } \\
\text { hibition stand accompanied by supporting } \\
\text { media" }\end{array}$ \\
\hline May & Assignment 4 & Reflective summary & $\begin{array}{l}\text { Their brief was to write a reflective } \\
\text { commentary on the work they had sub- } \\
\text { mitted for the three assignments for the } \\
\text { MDP1 Module, and their learning } \\
\text { throughout the year }\end{array}$ \\
\hline
\end{tabular}

The learning activities are looking to develop a number of qualities in the students, and Table 1 outlines the learning activities included in the module, aimed at developing some of the qualities listed below: 
- Confident to speak in public: several of the activities involved standing up to present work, for example presenting the outcomes of a seminar activity to the whole group.

- Technical skills: these were mainly developed through using Microsoft Office programs, including in particular Word, Excel, PowerPoint and Publisher.

- Innovative: a group activity to come up with a hypothetical business idea, and to "pitch" it to the assessors by means of an exhibition stand and presentation.

- Self-reliant: the students were expected to work autonomously, keeping to deadlines for assignments, and organising their own learning.

- Enthusiastic: it is a challenge to make some of the more basic skills appeal to students, especially those who had covered the material in previous learning, so to encourage enthusiasm, a novel or topical approach was taken to the teaching, always relating learning to the world of business.

- Self-reflective: reflection on the module and how it impacted upon their learning and development over the course of the module was encouraged in a final reflective assignment.

The module was delivered for the first time from September 2009 to June 2010, and there were just over 500 first year undergraduate students taking the module. The degree programmes these students were taking ranged from Business and Management Honours degrees, with different specialisms, such as finance, marketing and human resources, to Business Information Technology and foundation degrees in Business and Management. Also there were students taking hospitality, tourism, sport and leisure honours degrees and foundation degrees. Where group activities were included in the seminars or for assessment, students were able to form their own teams, from within their tutorial class.

In the next section there is a description of the methods used to collect data, upon which to evaluate the success of the module. This is followed by a section summarising the findings from the data collection and analysis.

\section{Research Methods}

This paper presents a case study of a module development, aimed at enhancing the teaching of IT within business programmes. As an interpretive study, evaluation uses a qualitative approach, allowing the researchers to determine the effectiveness of the new module in achieving the objectives.

The data used for evaluating the success of this new module came from the tutor's module evaluation, from the students' module evaluation questionnaire and a final reflective assignment, set as part of the portfolio of assessed exercises. The module evaluation questionnaire is completed for all modules as part of the ongoing quality assurance procedures. This questionnaire consists of a number of questions relating to satisfaction with the module administration, communication within the module and support from tutors, library and technical provision. However, in the research for this paper only the following three open ended questions were used in the analysis, as these provided more information on the students' opinions of the module content:

What did you find most useful about this module?

What did you find least useful about this module?

Are there any changes you would recommend making to this module?

The questionnaire was administered just before the end of the second teaching semester, as the students had given their group presentations for the third portfolio exercise. In the next two weeks the students had to submit their final reflective assignment, which was also used to gain an impression of the parts of the module most valued by these students, as they looked back on their 
learning over the year. Not all of the students included critical reflection on their learning in their final reflective assignment, but many of them did make comments relating to their changed impressions of the module as they looked back on the ways in which their skills had developed. Completing the questionnaire may have prompted some reflection on the module, which may have been further articulated in the final reflective assignment.

In the next section the findings are presented, and the six qualities we hoped to develop in students were used as a framework for analysing the data, by sorting all of the statements made according to these themes.

\section{Findings}

Although the response rate for completing the questionnaire was low (about 25\%), the 130 who did complete it, gave 170 positive comments, 41 negative comments, and several suggestions for ways in which the module could be improved, in answering the three open questions at the end of the questionnaire. Gathering feedback from students is difficult, and often the students who have participated most in the module delivery, are the only students who respond to evaluation questionnaires, and provide detailed feedback on the module. There was a hectic schedule as group presentations were being assessed, and the tutors were unable to chase students for return of their questionnaires, which contributed to the low response rate to the questionnaire. However, responses to the questionnaire were supplemented with comments from the students' final reflective assignment, adding to the richness of the qualitative data that was analysed. The following sections summarise the responses to the questionnaire and the reflective assignment in terms of the six qualities the module aimed to develop. Comments labelled Reflection, have been taken from the final reflective assignment, whilst other comments were from the questionnaire.

\section{Confident to Speak in Public}

Many of the positive comments referred to presentation skills and confidence, for example one student said "Learning how to stand out and be confident", which exactly mirrored our aims for the module. Others said that the presentation skills "helped confidence". Some of the students had learnt how to give a presentation previously, but for others this was a first time, and obviously valued as an employability skill. The lectures on giving presentations and presenting oneself were also mentioned as positive elements by several students, for example "how to conduct yourself in the work world".

The art of presenting and "selling" oneself and one's employer and products, was emphasised in the lectures and seminar activities, with some clear guidance on effective presentation, which was cited by some students. From the final reflective assignment one student's summary was this: "In conclusion, I have really enjoyed the Management Development Programme (MDP) module. It has helped me grow as a person and I know that working in a group you can still be heard and working alone is not scary. The assignment that I enjoyed the most has to be number 3 (Group presentation), even though it had its up and downs assignment 3 was the one that made me feel stronger as a person." (Reflection).

Another comment was "I have also learned about my abilities to work within a group and developed my confidence delivering presentations" (Reflection). The appreciation that confidence had been built was mentioned by several students in their reflective assignments, e.g. "From this I have gained confidence in myself and find it less stressful talking and pitching ideas in front of others; however I still need to put more emphasis on my presentation skills and with practice hope this will give me the presentation skills needed to be an asset to my employer in the near future", (Reflection). 


\section{Technical Skills}

The technical skills were based on the Microsoft Office Suite, with Excel, Word, PowerPoint and Publisher used in seminar and assignment activities. About 35 positive comments were given, including 17 mentioning Excel specifically, because the first assignment was designed to develop Excel skills, and this may have had the most impact on the students' learning,: "Working with Excel was wonderful'. Students entering the first year of the undergraduate programmes have a range of different ability levels, particularly in IT skills, so the exercises specifically aimed at developing these skills, were supported by the tutors in practical sessions. This enabled those who required more help with the exercises to have this help, whilst allowing those students who had already gained these skills to work unaided if they wished.

Thinking about their IT skills more generally, comments were made, such as: "Makes using a computer much simpler", and "By completing this assignment I have discovered that my main strengths are in IT skills in things such as Microsoft Excel" (Reflection). This next comment summarises nicely the purpose behind the module: "The MDP course has provided a toolkit of theories and techniques, many of which will be very useful throughout this consultancy project as well as my professional career in the future."

\section{Innovative}

One of the first seminar activities was to use PowerPoint to create a presentation to "sell" any sort of business idea to us. Although some students rose to the challenge and came up with wacky ideas, others were a little more restrained, as can be seen in the two examples in Figure 1.
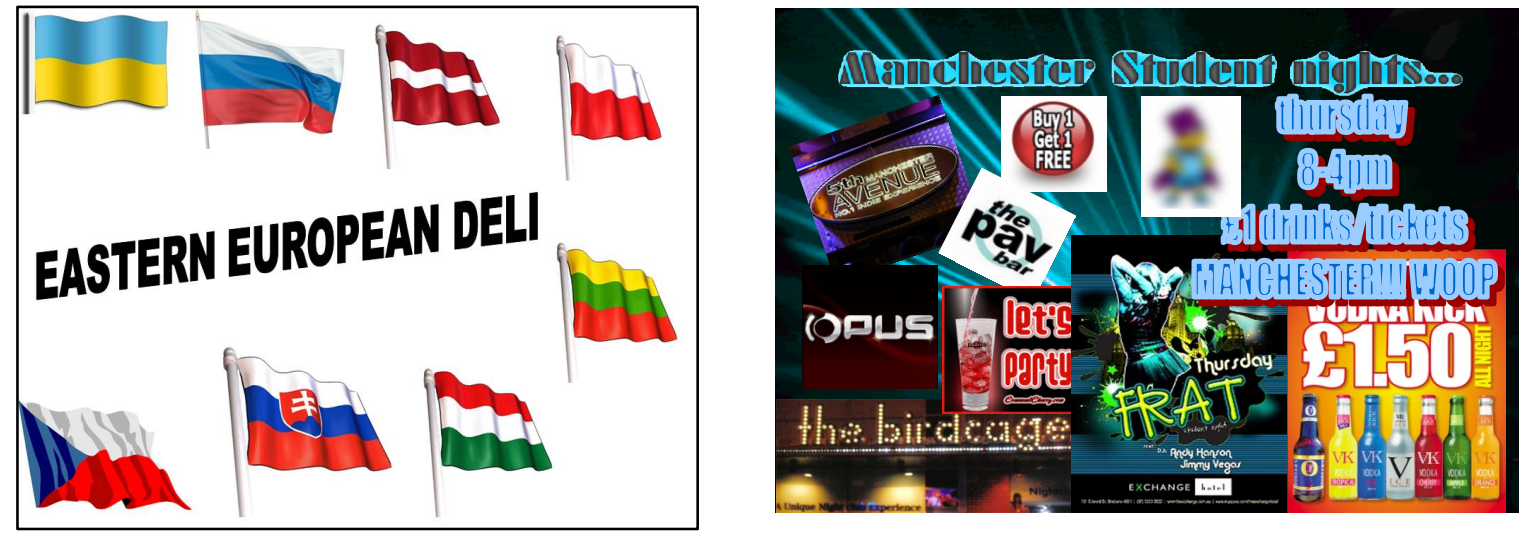

Figure 1 - Examples of innovative ideas presented by students on the MDP1 module.

Having developed some technical, presentation and communication skills through the seminar activities, the group assignment later in the year was to present a hypothetical business idea, and "sell" it to the tutors, using a range of presentation media. This allowed free rein to come up with an innovative idea, and to explore the real world potential for the idea. Again there were some unusual ideas (Two examples are given in Figure 2), and many that were innovative and have the potential to be developed as a business idea, such as "We decided for the purpose of the presentation we would be wedding planners, our business being called; Beautiful Brides to be. We found there was a lot of information on the internet informing us of this profession and researched into it to ensure we knew what the business would entail" (Reflection). Another idea was "Our group choose to do an around the world themed restaurant named "Foods of the World." This idea arose because Manchester is a city of many cultures. These cultures created the many restaurants Manchester offered, but our restaurant was to cover all cultures under one roof"' (Reflection). 

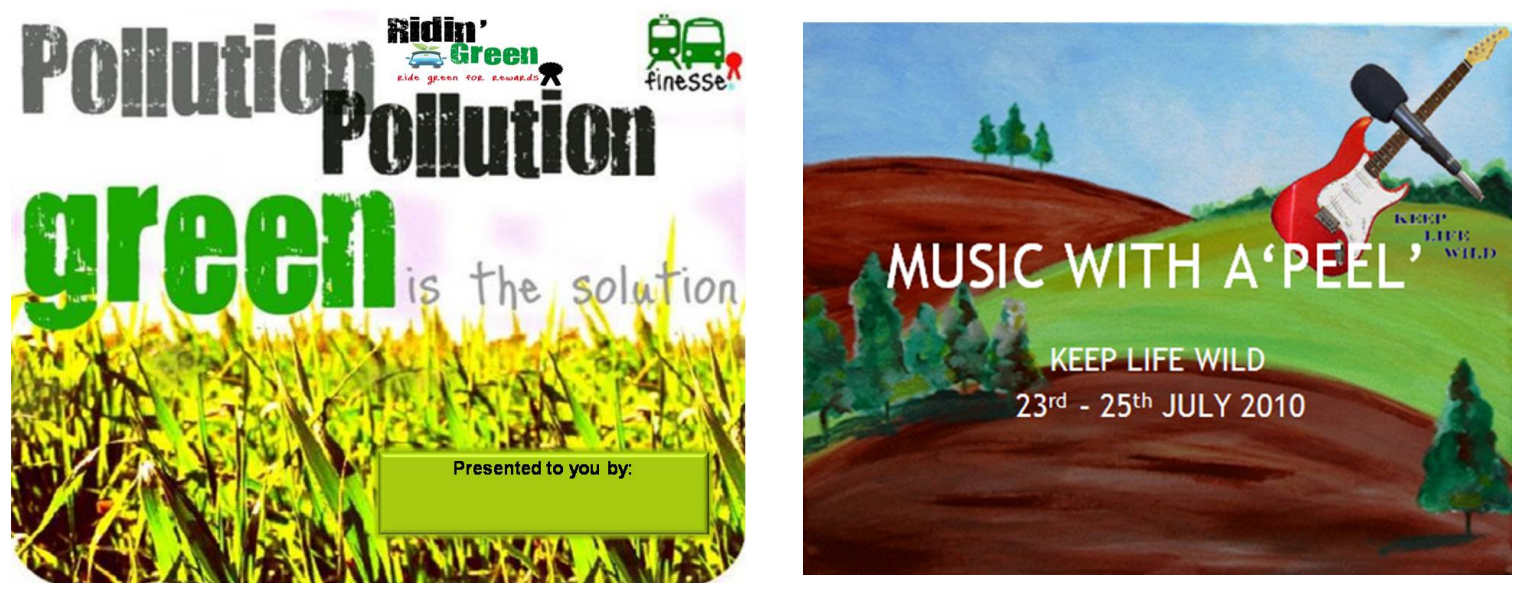

Figure 2 - Examples of innovative ideas produced by the MDP1 module groups.

\section{Self-reliant}

Group working, as well as being an important skill in its own right, is one vehicle for developing self-reliant individuals, because the groups have to organise themselves and the activities with minimal input from tutors. Working in a group was commented on positively by 13 students; and there were no negative comments, which is unusual for group working in higher education. Suggestions for changes included having more group working, and having students assigned to groups: "so you meet new people ". The module presented an opportunity for: "Learning new techniques with design, chance to present real life business stand, what to expect in business" (Reflection).

One set of seminar exercises was aimed at developing the students' research skills in the library and these were well accepted, and mentioned by about five of the students, for example: "I feel least confidence on researching and interpreting information from a variety of sources. By managing my free time on practising the e-library system I think that I will manage to cover my weakness. What is more, I noticed that the problem I have with referencing, may be because I have not occupied enough on it during previous years. My main goal now is to improve as much as I can my weaknesses so I have to attend referencing sessions during induction to $2^{\text {nd }}$ year, I have to read study skills booklet and finally I have to consult with module tutors" (Reflection). The realisation that undergraduate education is aimed at developing self-reliance was noted in the reflective assignment, by several students, for example this comment: "After analysing the 3 assignments done for this year in MDP, I came to realise that I could have done better if I put a lot of work to it, and most of all if I had learnt to think outside the box, in other words not to rely only on lectures, but to be able to apply this and experience more, with the help of computers provided everywhere in campus" (Reflection).

\section{Enthusiastic}

The intake of students for the undergraduate programmes in this school is very varied, and as a module designed to develop all of the students to a certain level of attainment, providing challenging and interesting learning activities that will motivate students at all levels is difficult. Although many students said that they already possessed good IT skills, most of them learned something through this module. One student said: "I embarked on this module with a fairly superficial idea of it, I had the assumption that it will be fairly simple", but later acknowledged that he had learnt quite a lot about presentations: "Project presentation really made me work hard. This is one of the most interesting presentations I have ever had to do" (Reflection). 
Integrating IT Skills into a Business School's Programmes

In particular, the group assignment was met with enthusiasm by many of the teams: "It is amazing the amount of camaraderie that is created in teams, especially when the going gets tough. People will often go to what seems like extreme lengths when they know that they can rely on the support and encouragement of the team" (Reflection). Similarly, other aspects of the module were met with some enthusiasm: "Overall, this module was exciting, fun and an experience for me, and I would advise students to give this module a try and experience the benefits for themselves" (Reflection).

\section{Self-reflective}

Teaching reflection can be a challenge, because taking the time to sit back and think of one's learning over a period is a skill that needs to be practiced. Students were asked to keep a learning $\log$ over the course of the module, and to note each week their achievements, learning, things that did not go to plan and things they need to work on in future. This was coupled with a skills assessment given to the students at the beginning of the module, then again at the end of the module, to prompt their thinking as they worked on the reflective assignment. Five of the students commented positively on the reflective content of the module.

Writing a CV could be regarded as mundane, as indeed it was for some students, but others found the experience new to them: "When I got to second semester my feeling about Management Development Program had changed; I was very scared because I did not have any experience in writing a good $C V$ and cover letter." Others found that the exercise encouraged them to reflect: "Then I look back at some of my previous CVs and all of them were out of date, missing information and had things that were not essential for an interviewer to know. Then I sat down and started gathering all of this information and realised that some places that I send my CV to did not call me back because the lack of structure in my old CV" (Reflection).

The final reflective assignment was also reflected upon, for example: "My conclusion from writing this reflective report is that this has helped give me an overview of my achievements over the last year doing this module this being because from doing each assignment this has assisted me in seeing my strengths and weaknesses when completing my portfolio for the $1^{\text {st }}$ year of this programme. This reflective assignment has highlighted to me my strengths, weaknesses from completing this report. I can now improve my skills in regards to turning my weaknesses into strengths in the $2^{\text {nd }}$ year of this programme" (Reflection). Another comment summarising the benefits of the module is: "In this module I have experienced a lot of problems and got to solve them, and I learned new things about myself. Also, I got to develop my skills in most areas to prepare myself for next year and to boost my future performance" (Reflection).

\section{Delivery and Content}

Most students liked the mix of lectures, practical seminars and portfolio of assessed tasks. The seminars were particularly appreciated because of the range of activities and the smaller classes meant that there was the possibility of greater interaction with the tutor. Overall the content of the module was well received, although some lectures were noted as "boring", because some students had covered those topics previously. The aim was to have "inspirational" lectures, but some lectures were obviously not met with enthusiasm by all of the students. Seminar activities were most appreciated for developing particular skills, so the mix of activities seemed to be about right.

The following quotes sum up the feelings of many of the students: "In conclusion I have gained a lot of skills, experience, knowledge and ideas from this module. Management Development Programme has enhanced my knowledge because at first I was unaware of how to produce leaflets, posters, business cards, organise an exhibition, link formulas, Excel skills, I had become more confident in PowerPoint presentations, I had also learnt how a good presentation is designed and 
made" (Reflection). "How time flies! The University life of first year is nearly finished. In this year, about 20 lectures and 10 seminar classes of Management Development Programme really taught me quite a lot" (Reflection).

\section{Proposals for Changes and Future Directions}

The new module was regarded by many as a success, and it did achieve the aims set out. Feedback from the students provided support for many activities that were included, and some suggestions for changes that could be incorporated in future delivery of the module. This section will detail the changes that are being included in the delivery for this year.

One key change was the order of delivery of lectures, associated seminar activities and assessment exercises. In order to involve the Personal Tutors more closely, the assessed activity of producing a CV was moved to become the first assessed element of the portfolio. Students were asked to produce a CV, submit their work, and arrange an interview with their Personal Tutor to receive feedback on their $\mathrm{CV}$. Running in parallel with this activity were seminars on using the computing facilities, using the Blackboard VLE (Virtual Learning Environment), and how to submit assignments. The Excel assignment followed, with tutorial support so that individuals can have more personal guidance.

Many of the comments on the evaluation questionnaire included the word "more", for example more practical work, more group work and more one to one tuition, but on the whole students were satisfied with the module as it was delivered. The IT skills developed within the module were regarded as valuable by many of the students who commented on them, but several students suggested there should be more IT skills, such as web page design.

\section{Conclusions}

As an exercise to enhance the IT skills of all of the students across Salford Business School, the module was successful. Right from the start of the module, IT skills were promoted, from using MS Excel to produce personal accounts, to MS Word for producing a CV and MS PowerPoint to present to an audience. IT is an important element of communication and "selling" oneself or a product, and the students engaged wholeheartedly with these learning activities. Students regarded the IT skills development activities as valuable, and combined with the employability skills development activities, the module has been an excellent learning experience for the students and the tutors. The range of ability levels of the students on this module proved to be a challenge for the tutors, and motivating all of the students was difficult. It was rewarding to read the final reflective assignments submitted by many of the students, which provided the tutors with justification to continue with the module in a largely unchanged format in the following year.

\section{References}

Dacre-Pool, L. \& Sewell, P. (2007). The key to employability: Developing a practical model of graduate employability. Education and Training, 49(4), 277-289.

Dillenbourg, P. (1999). Collaborative learning: Cognitive and computational approaches. Oxford: Elsevier.

Dunne, E., \& Rawlins, M. (2000). Bridging the gap between industry and higher education: Training academics to promote student teamwork. Innovations in Education and Teaching International, 37(4), 361-371.

Education. (2000). Academic standards - Librarianship and information management, QAA for HE: 6. Accessed November 2010 from http://www.qaa.ac.uk/academicinfrastructure/benchmark/honours/default.asp 
Integrating IT Skills into a Business School's Programmes

Education. (2007). General business and management, QAA for HE: 7. Accessed November 2010 from http://www.qaa.ac.uk/academicinfrastructure/benchmark/honours/default.asp

Edwards, G. (2005). Connecting PDP to employer needs and the world of work. HEA. AccessedSeptember 2007 from http://www.heacademy.ac.uk/resources/detail/id71_connecting pdp_edwards

Gallup. (2010). Employers' perception of graduate employability. European Commission [Flash EB series \#304, 2010.]. Accessed February 2011 from http://ec.europa.eu/public_opinion/archives/flash_arch_314_300_en.htm\#304

Hodkinson, P., \& Macleod, F. (2007). Contrasting concepts of learning and contrasting research methodologies. Proceedings of Educational Research and TLRP, Cardiff, Wales, 26th to 27th November 2007.

Hordyk, V. (2007). A convergence of perspectives: Enhancing students' employability. In E. O'Doherty (Ed.): The Fourth Education in a Changing Environment Conference Book 2007 (pp. 353-372). Santa Rosa, CA: Informing Science Institute.

Hyland, T., \& Johnson, S. (1998). Of cabbages and key skills: Exploding the mythology of core transferable skills in post-school education. Journal of Further and Higher Education, 22(2), 163-172.

Knowles, M. (1990). The adult learner a neglected species. Houston, TX: Gulf Publishing.

McConnell, D. (2000). Implementing computer supported cooperative learning (2nd ed.). Kogan Page.

Prichard, J., Stratford, R., \& Bizo, L. (2006). Team-skills training enhances collaborative learning. Learning and Instruction, 16, 256-265.

Prospects. (2007). What do graduates do? Accessed Nov 2007 from http://www.prospects.ac.uk/what_do_graduates_do_employers.htm

Schunk, D. (2000). Learning theories: An educational perspective. New Jersey: Prentice-Hall.

Sfard, A. (1998). On two metaphors for learning and the dangers of choosing just one. Educational Researcher, 27(2), 4-13.

Yorke, M., \& Knight, P. (2003). The undergraduate curriculum and employability. LTSN Generic Centre, Accessed-April 2003.

\section{Biographies}

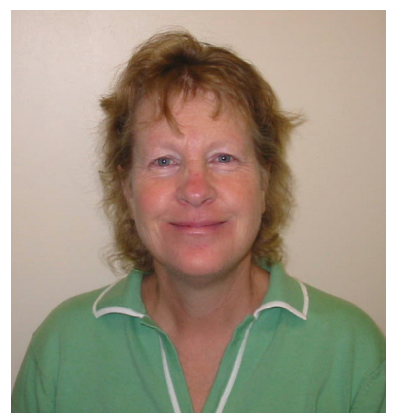

Janice Whatley is a lecturer in Salford Business School at the University of Salford. Janice has a doctorate in information systems from the University of Salford, within which the Guardian Agent system for supporting student team projects was created. Janice has also published in the areas of improving teaching and learning for students in higher education, and developing IT and team working skills, and she is a member of the Information Systems, Organisations and Society Research Centre. Janice is also interested in encouraging collaboration between students, having recently co-ordinated the European funded CAB Project, to enable students to learn through collaborating online with students from other European countries (www.cabweb.net). Her teaching includes multimedia, e-learning, team working and IT skills development. She is the school's Employability Champion and Retention Officer, so student progression and careers is very important in her work. 


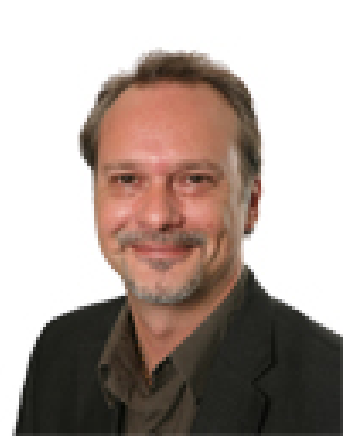

Simon Ireland is currently working as the Undergraduate Programme Leader for the Leisure Management suite of programmes within Salford Business School, University of Salford (UK). My teaching focus lies within communication/management methods within the international tourism sector.

My research interests have included the use of Computer Assisted Learning tools in higher education, leisure related urban regeneration, and social housing. I am currently researching the use of global communication technologies for the backpacking community, looking at how the developments in technology impact on the experiences of long term independent travellers. Including both how technology can assist the experience and also how it is used as a tool for personal communication within the community and the effects this can have on local communities.

Richard Bell. After studying International Business Studies at The

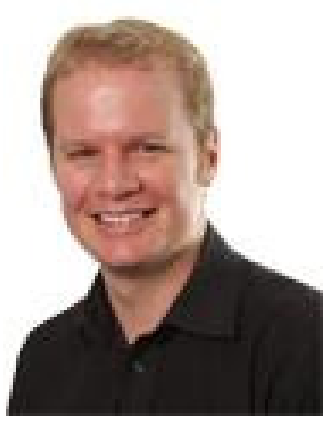
University of Salford, I went on to open an Overseas Student Recruitment agency that operates in the UK and the Middle East. Having established links and contracts with UK Institutions, I handed the business to my partner and accepted an offer to join the teaching staff at the University of Salford, where I have been lecturing for nine years. My teaching includes Management Development Programme 1, Management Simulation, Accounting Principles and Destination Analysis - an Erasmus Intensive Programme. Having set up the Business School's first international Intensive Programme (IP) I have gone on to coordinate the development of new IP's within the Leisure Industries Division of the school.

Currently I am researching the role of information sources in the consumer decision making process. This research will include the evolution of information systems, consumer behaviour, decision making processes and involvement theory. 